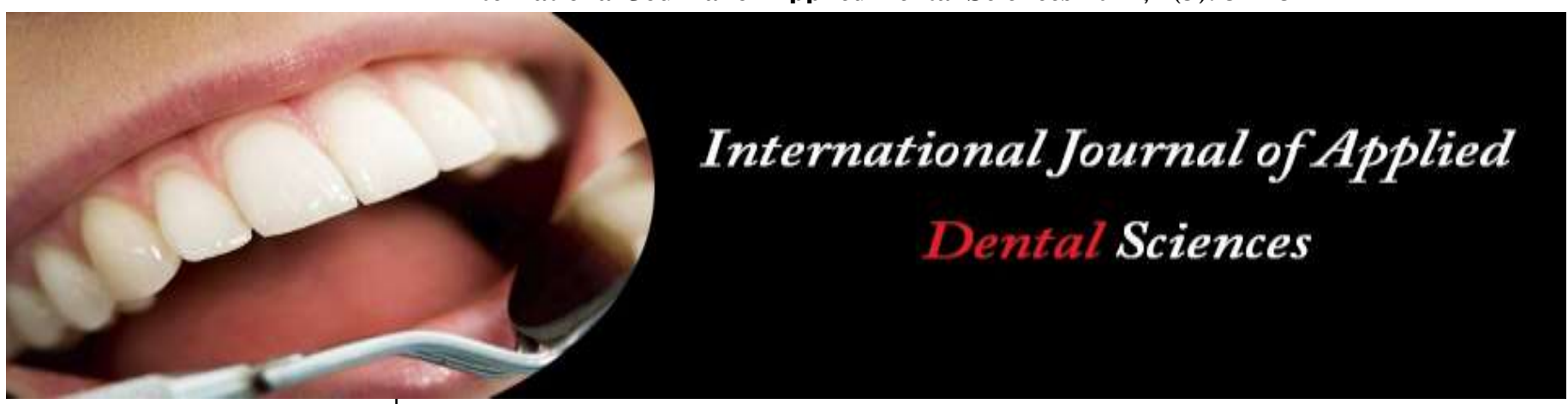

ISSN Print: 2394-7489

ISSN Online: 2394-7497

IJADS 2021; 7(3): 314-321

(C) 2021 IJADS

www.oraljournal.com

Received: 18-05-2021

Accepted: 21-06-2021

Abhiroop Singh

Registrar, Department of Oral and Maxillofacial Surgery, Indira Gandhi Government Dental

College, Jammu, Jammu and Kashmir, India

Parveen Akhtar Lone

Professor and HOD,

Department of Oral and

Maxillofacial Surgery, Indira

Gandhi Government Dental

College, Jammu, Jammu and

Kashmir, India
Corresponding Author:

Abhiroop Singh

Registrar, Department of Oral and Maxillofacial Surgery, Indira

Gandhi Government Dental

College, Jammu, Jammu and

Kashmir, India

\section{Evaluation of post traumatic neurosensory disturbances in the distribution of inferior alveolar nerve in case of mandibular fractures and their management}

\author{
Abhiroop Singh and Parveen Akhtar Lone
}

DOI: $\underline{\text { https://doi.org/10.22271/oral.2021.v7.i3e.1318 }}$

Abstract

Objective: The purpose of this study is to evaluate and document the neurosensory changes in the distribution of inferior alveolar nerve associated with mandibular fracture fixation.

Patients and Methods: This was a evaluation carried out in the Department of Oral \& Maxillofacial Surgery, Indira Gandhi Government Dental College, Jammu from July 2019 to July 2021. A total of 40 patients were included in the study as per the inclusion criteria. All these forty patients had fractures of the mandible between the lingula and the mental foramen. They were then evaluated with respect to the etiological factors, fracture displacement, neurosensory deficit, subjective findings, objective findings and the treatment employed to treat the mandibular fractures. The standard treatment protocol applied was either closed reduction or open reduction with internal fixation under local anaesthesia or general anaesthesia.

Results: The subjective neurosensory deficit was seen in $12(30.0 \%)$ subjects and the Objective Neurosensory Deficit was seen in $21(52.5 \%)$ subjects. The displacement of fracture less than $5 \mathrm{~mm}$ was seen in $23(57.5 \%)$ patients, displacement more than $5 \mathrm{~mm}$ was seen in $7(17.5 \%)$ patients and no displacement was seen in $10(25.0 \%)$ patients. The treatment CR with MMF was done for $33(82.5 \%)$ patients and ORIF was done for $7(17.5 \%)$ patients. Thirty three patients out of the total 40 patients who were treated by closed reduction and MMF, reported no residual paresthesia.

Conclusions: Open reduction and internal fixation, fracture displacement of $5 \mathrm{~mm}$ or more and severity of nerve injury were associated with an increased risk for deterioration of the IAN neurosensory deficit after treatment of mandibular fractures and in majority of patients with IAN injury, sensory function recovered in 3 months.

Keywords: Inferior alveolar nerve, fracture mandible, neurosensory deficit, paraesthesia, open reduction, closed reduction

\section{Introduction}

Mandible is considered to receive maximum impact during any trauma, and hence it is the most common bone to sustain injury in the form of fracture ${ }^{[1]}$. Accurate statistical data is difficult to obtain as there are many variables associated with the studies. There also exists diversity in data when studies are compared from various countries throughout the world [2]. Despite the diversity of statistical data in the incidence of mandibular fractures and their cause, the primary aetiology is attributed to vehicular accidents (43\%) followed by assaults (34\%), work related injuries $(7 \%)$, fall $(7 \%)$, sports related injuries $(4 \%)$, and other miscellaneous causes.

The high incidence of mandibular fractures is primarily attributed to thinner cross sectional area, muscle attachments that alter the biomechanics of fracture and the presence of third molars ${ }^{[3]}$

Mandible encloses vital neurovascular bundle comprising of the inferior alveolar nerve and vessels. The inferior alveolar nerve [IAN] is positioned in the mandibular canal, which protects it from any physical insult; nevertheless the IAN may be injured during any violation of the mandibular canal, trauma being one of the cited reasons. 
The injury so sustained may be manifested as loss/altered sensory function of the chin and the lip region ${ }^{[4]}$.

Fractures of the mandible most often lead to neurosensory deficit of IAN. This may be attributed to the fact that either the IAN lies in direct line of fracture thereby facing primary insult or may be injured as a result of secondary insult during manipulation or fixation of the fracture fragments.

The prevalence of IAN deficit ranges from $5.7 \%$ to $58.5 \%$ in post-injury/pre-treatment cases and $0.4 \%$ to $91.3 \%$ in post treatment cases. Permanent nerve function deficit ranges from $0.9 \%$ to $66.7 \%{ }^{[5,6,7]}$.

These neurosensory changes, either improving or worsening have to be quantified and documented to reach definitive conclusions. This needs a systematic acquisition of data, obtained via specific investigative tests that record both subjective and objective variations ${ }^{[8]}$. Seddon in 1943 classified nerve injuries into three categories i.e. Neuropraxia which is an interruption in conduction of the impulse down the nerve fiber; Axonotmesis which is loss of the relative continuity of the axon and its covering of myelin and Neurotmesis which is complete transection of nerve.

The treatment goals of mandibular fractures on the other hand include restoration of pre-traumatic form and function. This goal can be achieved by anatomical reduction and stable fixation of the fractured fragments. This not only restores the pre-morbid dental occlusion but also provides optimal function of the mandible. Open reduction with internal fixation as per Champy's principles of osteosynthesis is a time tested method for fixation of mandibular fractures ${ }^{[9,10]}$.

There are various diagnostic tests that can be of aid in predicting as well as determining the degree of nerve injury. Clinical neurosensory testing is one of those diagnostic tests. Neurosensory testing can be divided into two basic categories, mechanoceptive and nociceptive testing, based on specific receptors stimulated through cutaneous contact. Mechanoceptive testing is based on Two-point discrimination, Static light touch and Directional discrimination. Nociceptive testing is by Pinprick and Thermal discrimination ${ }^{[11,12]}$.

There are some "gold standard" testing algorithms as suggested by Zuniga and Essick (1992) ${ }^{[13]}$ and the modified British medical research council scale which was originally meant for upper extremities which was modified by Mackinnon and Delon (1988) ${ }^{[14]}$ for grading trigeminal nerve injuries.

However, such algorithms are seldom used in clinical practice, as they are time consuming. The recent studies have failed to provide a comprehensive yet complete method of evaluating neurosensory function. Such a study may throw more light on evaluation and methodology thus helping us modifies present day treatment methods in order to limit or avoid neurosensory deficits that may arise as a result of mandibular fractures and its management.

\section{Patients and Methods}

The patients of maxillofacial trauma attending the OPD at the Department of Oral \& Maxillofacial Surgery, Indira Gandhi Government Dental College, Jammu were evaluated for mandibular fractures. Those satisfying the inclusion and exclusion criteria underwent neurosensory evaluation for the function of IAN. This was followed by either closed reduction or open reduction with internal fixation under local anaesthesia or general anaesthesia at our institute from July 2019 to Aug 2021. The inclusion criteria included:- 1) Fracture mandible between the lingula and the mental foramen of the mandible, 2) both the sexes, 3) age between 18-60 years, 4) systemically healthy patients and 5) level of mental status permitting an adequate neuro-sensory examination. The Exclusion criteria included:- 1)Multiple fractures of the mandible, 2) mandibular fractures proximal to the lingula and distal to mental foramen, 3) systemic disorders tending to affect the outcome of the study, 4) patients with difficulty in follow-up and5) expression of non-consent towards the requirement/protocol of the study.

Minimum of 40 cases of clinically and radiologically diagnosed mandibular fracture satisfying the inclusion and exclusion criteria were selected. All the cases underwent thorough clinical and radiological assessment for mandibular fracture. The patients were given a short questionnaire form for their own assessment of their neurosensory function in relation to IAN; which consisted of the following questions:

- What complaints do you have?

- What kind of sensation do you have in the area over the chin of the affected side?

- What kind of sensation did you have after the fracture and after the treatment?

- Did the sensation improve or worsen after surgery?

The patients were tested for Two Point Discrimination (TSD), Brush Directional Stroke (BDS), Static light touch (SLT), Thermal Discrimination (TD) and Subjective Response (SR). The Two Point Discrimination test was designed to test for the large, myelinated slow adapting A alpha sensory nerve fibres. Static Light Touch was for large myelinated, quickly adapting sensory nerve fibres. The Brush Directional Stroke test was utilized to assess large myelinated quickly adapting A alpha sensory nerve fibres. Thermal Discrimination test was designed to test for small myelinated, unmyelinated, A delta and $\mathrm{C}$ sensory nerve fibres. Scoring of neurosensory evaluation was carried out using visual analog scale (VAS) [11]. 


\begin{tabular}{l}
\hline Visual Analog Scale (VAS) on sensory chan ges in the lower lip and chin following \\
surgical procedure \\
How would you describe the sensation of your lower lip and chin. Place a vertical mark on the \\
line below to indicate the sensation on your lower lip and chin today. \\
No sensation \\
Place a vertical mark on the line below to indicate the level of sensation on your lower lip and \\
chin you find acceptable in daily life. \\
No sensation \\
Other comments:
\end{tabular}

The cutaneous soft tissues innervated by the mental nerve were tested for evaluation of IAN functioning and the methodology for testing of the cutaneous areas was adapted from Akal et al. 2000; 29(5): 331-336. All cases were managed by the same team of consultants. During the procedure the patients were asked to close their eyes. Each site was tested three times, and a correct response was considered two out of three appropriate answers. The tested site was compared with contralateral normal side to obtain correct response which was recorded as either normal $(\mathrm{N})$ or abnormal (A) according to the grading algorithm described by Zuniga and Essick. Neurosensory changes were evaluated pre-operatively, post operatively after 1 week, 3rd week, 6th week, 3 months and 6 months

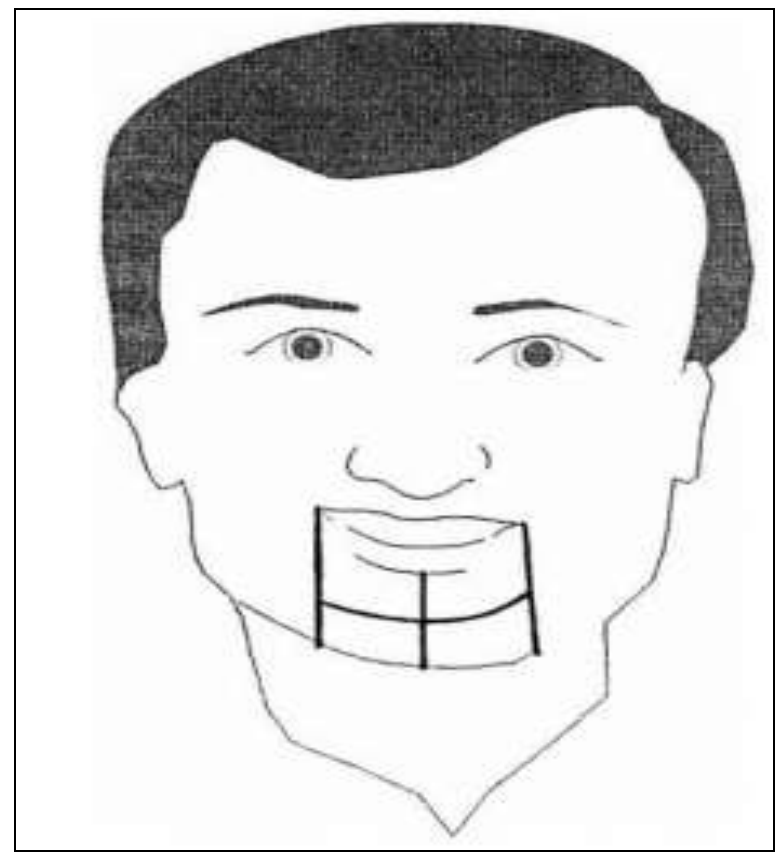

Fig 1: Adapted from Akal et al. 2000; 29(5): 331-336 


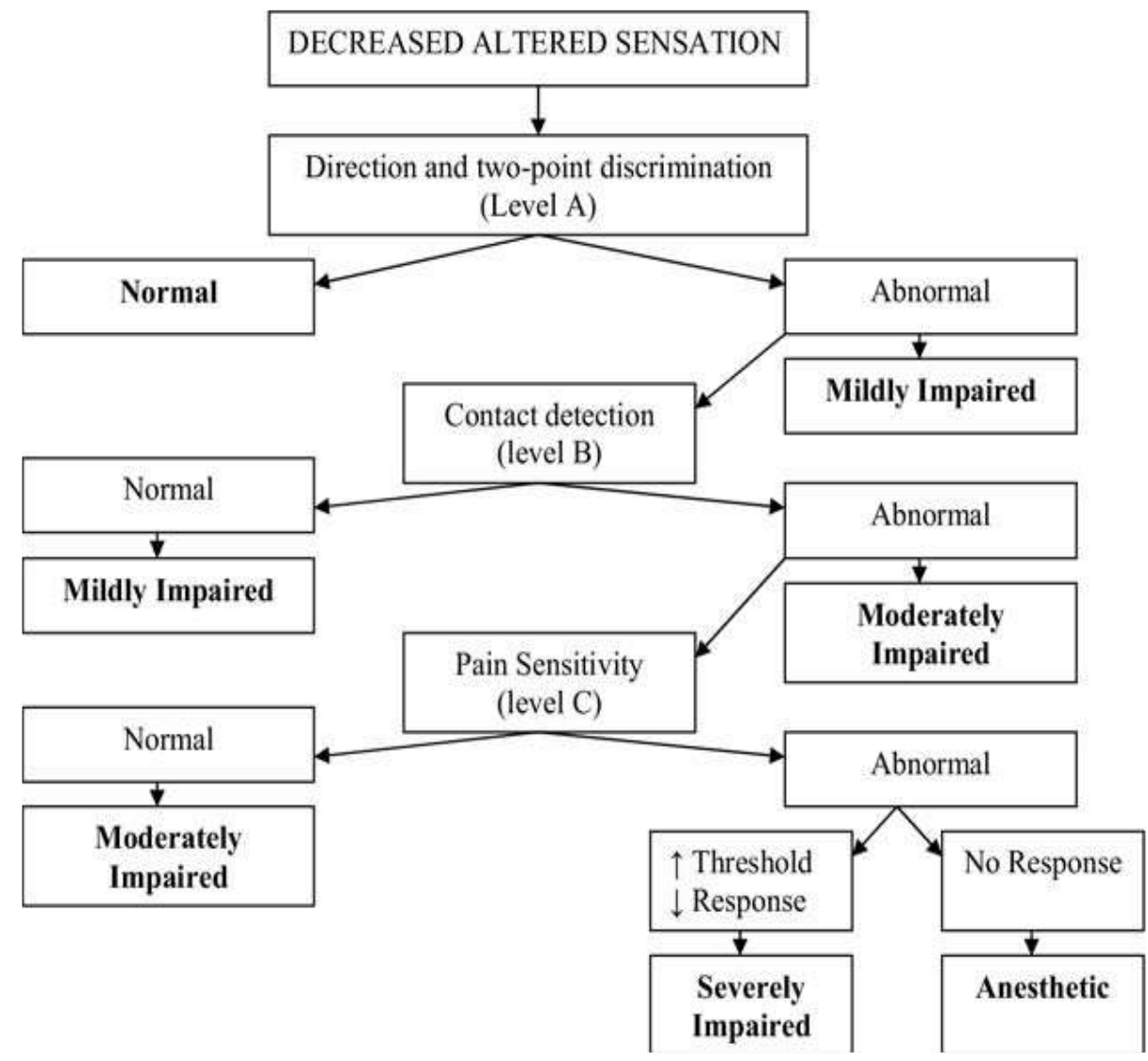

Fig 2: Grading algorithm for evaluating trigeminal nerve injury (Zuniga and Essick, 1992).

\section{Analysis of Data}

All data were recorded and maintained on an Excel spreadsheet (Microsoft, Inc, Redmond, WA). The statistical analysis was done with the help of SPSS (statistical package for social sciences) version 21.0 and Epi-info version 3.0 statistical Analysis Software. The significance of differences was assessed using Chi-square test, Mcnemar Chi-square test as appropriate.

\section{Results}

Forty patients were included in the study, out of which 34 were males and 6 were females. overall mean age of the study population was $27.13 \pm 10.13$ years (range 18-58 years).

In the study thirty four out of the 40 patients were males while only six patients were females, with male to female ratio of 5.67:1. This ratio was attributed to the fact that males are more prone to facial injuries due to road traffic accidents owing to negligent driving of two wheelers, violation of traffic rules, over-speeding, more exposure to outdoor games, brawls due to violent behaviour, warfare etc.

Out of the total forty patients, $30 \%$ patients $(n=12)$ reported subjective neurosensory deficit in the preoperative periods, whereas $52.5 \%$ patients $(n=21)$ had objective neurosensory deficit. Eighteen (45\%) patients were free from both subjective objective signs of paraesthesia at the time of preoperative testing.

Out of the 12 patients who demonstrated subjective signs of paraesthesia, 11 also showed objective signs of paraesthesia. However 1 patient did not show any objective signs. On the other hand out of the 21 patients who demonstrated objective signs of paraesthesia 10 did not report any subjective paraesthesia. This indicates that objective testing is a better tool to assess the paraesthesia.

The inter-interval comparison of each test was calculated individually for rate of recovery and most significant recovery of sensation in general (15\%) took place in the 3 weeks to 6 weeks interval as far as the two point discrimination, Directional discrimination, Light touch tests are concerned. The most significant recovery $(12.5 \%)$ for Thermal discrimination and Pinprick sensations was seen between intervals of 3 weeks to 6 weeks and 6 weeks to 3 months.

The displacement of the fractures was analysed using radiographs. The number of patients who had less than $5 \mathrm{~mm}$ fracture displacement were $57.5 \%(\mathrm{n}=23), 17.5 \%$ patients had more than $5 \mathrm{~mm}(\mathrm{n}=7)$ and $25 \%(\mathrm{n}=10)$ had no fracture displacement. Patients who had fracture displacement more than $5 \mathrm{~mm}(\mathrm{n}=7,17.5 \%)$ were treated by open reduction and internal fixation (ORIF) with maxillo-mandibular fixation (MMF) and those who had fracture displacement less than $5 \mathrm{~mm}$ or no fracture displacement were treated by closed reduction and MMF respectively $(n=33,82.5 \%)$.

None of the 18 patients who were free from paraesthesia preoperatively, developed any subjective or objective signs of paraesthesia in the postoperative intervals (irrespective of type of treatment). All patients who underwent closed reduction and MMF showed complete resolution of paraesthesia. However, out of the seven patients who had fracture displacement more than $5 \mathrm{~mm}$ and were treated with ORIF, $4(57.14 \%)$ patients had residual paraesthesia in the $6^{\text {th }}$ month also. This could be correlated to higher degree of displacement of fracture leading to more severe of injury of the IAN.

\section{Discussion}

The face and in particular the oral and perioral regions, are among the areas with high density of peripheral receptors. It is difficult to tolerate neurological disturbances in oral and maxillofacial areas compared to disturbances in other parts of the body.

Pain, temperature, touch, pressure, and proprioception (sense 
of body position) are transmitted centrally from the perioral structures via the inferior alveolar, lingual, infraorbital and mental nerves. Each of these sensations is carried out by different types of sensory receptors and nerve fibres, each showing different susceptibility to injury and variable recovery. Facial injuries constitute about $3.2 \%-8 \%$ of all injuries and $79.7 \%$ of all facial injuries involve mandible. Angle of the mandible is the weakest region and account for about 18\%-30\% of mandible fracture. Despite its good density, the mandible is reported to be the most commonly fractured bone of the facial skeleton probably due to its prominent and exposed position ${ }^{[28]}$. In another study it was stated that the inferior alveolar nerve (IAN) is positioned in the mandibular canal, where it is protected from direct injury. However, when the mandibular canal is violated the IAN is prone to injury. Injury varies in severity but often results in loss of sensory function in the lower lip and chin. This may compromise talking, drinking, and eating ${ }^{[11]}$.

There are various diagnostic tests that can be of aid in predicting as well as determining the degree of nerve injury. Clinical neurosensory testing is one of those diagnostic tests.

Neurosensory testing can be divided into 2 basic categoriesmechanoceptive and nociceptive testing-based on the specific receptors stimulated through cutaneous contact. Mechanoceptive testing can be divided based on 2-point discrimination (TPD), static light touch and brush directional stroke. Nociceptive testing is subdivided into pinprick and thermal discrimination. Zuniga et al. (1992) ${ }^{[13]}$ described a testing algorithm for grading trigeminal nerve injury based on several clinical sensory tests to determine the level of severity.

The age of the patients in our study ranged from 18-58 years with predominant age group of $18-30$ years. These findings are similar with the results of the studies conducted by Wong KH (2000) ${ }^{[24]}$. The mean age of male patients was $27.85 \pm 10.63$ years, the mean age of the female patients was $23.00 \pm 5.62$ and the overall mean age of the study population was $27.13 \pm 10.13$ years.

In the present study various etiological factors namely assault, fall, road traffic accidents and sports injuries were recorded with a frequency percentage of $10 \%, 25 \%, 52.5 \%$ and $12.5 \%$ respectively.

In a study, it was reported that the frequency percentage of injuries caused by assaults was $30.7 \%$ patients, missile injuries was $26.9 \%$, road traffic accidents (RTA) was $23 \%$, fall from height $(\mathrm{FFH})$ was $5.7 \%$, industrial injuries was $7.7 \%$, sports injuries was $3.8 \%$ and animal induced injuries was $1.9 \%{ }^{[30]}$. Another study found that the most common cause of the fracture was traffic accident $(n=15)$, followed by interpersonal violence $(n=3)$ and falls $(n=1)^{[5]}$.

In our study out of the total forty patients, $30 \%$ patients $(n=12)$ reported subjective neurosensory deficit in the preoperative periods, whereas $52.5 \%$ patients $(n=21)$ had objective neurosensory deficit which is in co-relation with the studies conducted by Halpern LR et al. (2004) [25] and Schultze - Mosgau S et al. (1999) ${ }^{[20]}$

Along with this, in our study the subjective evaluation was done by a standard questionnaire adapted from Poort LJ et al (2009) [11]. Further, the visual analog scale (VAS) was employed to carry out neurosensory evaluation. The VAS is an uninterrupted unmarked horizontal line, $100 \mathrm{~mm}$ in length, anchored by word descriptors at each end. The objective evaluation was done by using the protocol devised by Zuniga JR et al. (1993) ${ }^{[33]}$ for evaluating the neurosensory deficit.

Eighteen (45\%) patients were free from both subjective orobjective signs of paraesthesia at the time of preoperative testing. The cutaneous area which was used for evaluation of neurosensory examination in the study included the area supplied by mental nerve near the parasymphysis region extraorally over the affected side and the contralateral side of the same patient was used as the control. This was done as outlined by Akal UK et al. (2000) [23].

In the present study the rate of recovery for all the tests employed was statistically calculated and analysed individually. The inter-interval comparison of each test was calculated individually for rate of recovery and it was found that it improved significantly through preoperative period and postoperative 1 week, 3 weeks, 6 weeks, 3 months and 6 months respectively. In a study conducted by Rehman A et al. (2014) ${ }^{[34]}$, it was observed that rapid recovery was seen at Level B (light touch) sensation during first week than Level A neurosensory testing (Directional stroke and two point discrimination) and complete recovery of light touch sensation at four months follow up post operatively. The reason as explained in the studies conducted by Nishioka GJ et al. (1987) [9], was the fast recovery of small diameter myelinated and non-myelinated fibres containing light touch, thermal and nociception sensibilities than large diameter myelinated fibres conducting discriminative sensibilities i.e. 2 point and direction discrimination. However in our study the recovery patterns for Level $\mathrm{A}, \mathrm{B}$ and $\mathrm{C}$ were almost similar during various intervals.

Clinical experience suggests that nerve recovery can take many months to occur, although it has been suggested that most of the improvement will occur within the first week and it reaches its apex at 3 months ${ }^{[5,27,23]}$. In our study most patients showed recovery at 3 months interval, however, 4 $(10 \%)$ patients did not show recovery even at 6 months period indicating severely impaired nerve function.

In a study conducted by, it was observed that rapid recovery was seen at Level B (light touch) sensation during first week than Level A neurosensory testing (Directional stroke and two point discrimination) and complete recovery of light touch sensation at four months follow up post operatively ${ }^{[34]}$. The reason as explained in the studies conducted was the fast recovery of small diameter myelinated and non-myelinated fibres containing light touch, thermal and nociception sensibilities than large diameter myelinated fibres conducting discriminative sensibilities i.e. 2 point and direction discrimination ${ }^{[9]}$. However in our study the recovery patterns for Level A, B and C were almost similar during various intervals.

The rate of recovery of inferior alveolar nerve injury depends upon the severity of the nerve injury. The inferior alveolar nerve injury was classified into mild, moderate and severe injury and found that recovery period was prolonged with the increase in severity of injury ${ }^{[28]}$. A study reported prolonged recovery time of inferior alveolar nerve sensory function extending from 6 weeks to 5 months in comminuted and displaced fractures which indicates severe nerve injury associated with these types of fractures ${ }^{[30]}$.

Patients who had fracture displacement more than $5 \mathrm{~mm}(\mathrm{n}=7$, $17.5 \%$ ) were treated by open reduction and internal fixation (ORIF) with maxillo-mandibular fixation (MMF) and those who had fracture displacement less than $5 \mathrm{~mm}$ or no fracture displacement were treated by closed reduction and MMF respectively $(n=33,82.5 \%)$. This was in accordance with the studies conducted by Halpern LR et al. (2004) ${ }^{[25]}$, Mayrink G et al. (2012) ${ }^{[5]}$.

In the present study none of the 18 patients who were free from paraesthesia preoperatively, developed any subjective or objective signs of paraesthesia in the postoperative intervals 
(irrespective of type of treatment). All patients who underwent closed reduction and MMF showed complete resolution of paraesthesia. However, out of the seven patients who had fracture displacement more than $5 \mathrm{~mm}$ and were treated with ORIF, $4(57.14 \%)$ patients had residual paraesthesia in the $6^{\text {th }}$ month also. This could be correlated to higher degree of displacement of fracture leading to more severe of injury of the IAN.

In a study it was specifically stated that patients with a fracture displacement greater than $5 \mathrm{~mm}$ had a 6 fold increased risk for an adverse effect on the neurosensory score after treatment compared with patients with fractures displaced $5 \mathrm{~mm}$ or less. They also stated that, compared with closed reduction and IMF, patients undergoing ORIF had a 40 -fold increased risk of a worsening of IAN sensory score after treatment ${ }^{[25]}$.

Patients with mandibular fracture are a difficult population to study, because of the non-elective nature and because of the high chance of accompanying fractures ${ }^{[11]}$. The present study established the incidence and recovery patterns of IAN deficit following mandibular fractures and their treatment. It was conducted on 40 patients with a follow up period of 6 months postoperatively. The limitations of a smaller sample size are one of the drawbacks of the study. It is recommended that a multi-centric study should be conducted with a larger sample size to further establish the neuro sensory behaviour patterns in mandibular fracture. This would be further helpful in developing guidelines for surgical intervention of mandibular fractures from a neurologic standpoint.

\section{Results}

Table 1: Age profile of patients (years)

\begin{tabular}{|c|c|c|}
\hline & Mean & Std. Deviation \\
\hline Male & 27.85 & 10.63 \\
\hline Female & 23.00 & 5.62 \\
\hline Over-all & 27.13 & 10.13 \\
\hline
\end{tabular}

Table 2: Distribution of the patients with regard to the subjective neurosensory deficit

\begin{tabular}{|c|c|c|}
\hline Neurosensory Deficit (Subjective) & Frequency & Percent \\
\hline No & 28 & $70.0 \%$ \\
\hline Yes & 12 & $30.0 \%$ \\
\hline Total & 40 & $100.0 \%$ \\
\hline
\end{tabular}

Table 3: Distribution of the patients with regard to the objective neurosensory deficit

\begin{tabular}{|c|c|c|}
\hline Neurosensory Deficit (Subjective) & Frequency & Percent \\
\hline No & 19 & $47.5 \%$ \\
\hline Yes & 21 & $52.5 \%$ \\
\hline Total & 40 & $100.0 \%$ \\
\hline
\end{tabular}

Table 4: Comparison of two point discrimination deficit at various time intervals

\begin{tabular}{|c|c|c|c|c|c|c|}
\hline Two point discrimination deficit & Pre-operative & 1 Week & 3 weeks & 6 weeks & 3 months & 6 months \\
\hline \multirow{2}{*}{ No } & 19 & 20 & 24 & 30 & 36 & 36 \\
\hline & $47.5 \%$ & $50.0 \%$ & $60.0 \%$ & $75.0 \%$ & $90.0 \%$ & $90.0 \%$ \\
\hline \multirow[t]{2}{*}{ Yes } & 21 & 20 & 16 & 10 & 4 & 4 \\
\hline & $52.5 \%$ & $50.0 \%$ & $40.0 \%$ & $25.0 \%$ & $10.0 \%$ & $10.0 \%$ \\
\hline \multirow[t]{2}{*}{ Total } & 40 & 40 & 40 & 40 & 40 & 40 \\
\hline & $100.0 \%$ & $100.0 \%$ & $100.0 \%$ & $100.0 \%$ & $100.0 \%$ & $100.0 \%$ \\
\hline
\end{tabular}

Table 5: Comparison of directional discrimination deficit at various time intervals

\begin{tabular}{|c|c|c|c|c|c|c|}
\hline Directional Discrimination deficit & Pre-operative & 1 Week & 3 weeks & 6 weeks & 3 months & 6 months \\
\hline \multirow{2}{*}{ No } & 19 & 20 & 24 & 30 & 33 & 36 \\
\cline { 2 - 7 } & $47.5 \%$ & $50.0 \%$ & $60.0 \%$ & $75.0 \%$ & $82.5 \%$ & $90.0 \%$ \\
\hline \multirow{2}{*}{ Yes } & 21 & 20 & 16 & 10 & 7 & 4 \\
\cline { 2 - 7 } & $52.5 \%$ & $50.0 \%$ & $40.0 \%$ & $25.0 \%$ & $17.5 \%$ & $10.0 \%$ \\
\hline \multirow{2}{*}{ Total } & 40 & 40 & 40 & 40 & 40 & 40 \\
\cline { 2 - 7 } & $100.0 \%$ & $100.0 \%$ & $100.0 \%$ & $100.0 \%$ & $100.0 \%$ & $100.0 \%$ \\
\hline Chi-square value $=29.550, \mathrm{p}$-value $<0.001 *$
\end{tabular}

Table 6: Comparison of light touch deficit at various time interval

\begin{tabular}{|c|c|c|c|c|c|c|}
\hline Light touch deficit & Pre-operative & 1 Week & 3 weeks & 6 weeks & 3 months & 6 months \\
\hline \multirow{2}{*}{ No } & 20 & 20 & 24 & 30 & 36 & 36 \\
\cline { 2 - 7 } & $50.0 \%$ & $50.0 \%$ & $60.0 \%$ & $75.0 \%$ & $90.0 \%$ & $90.0 \%$ \\
\hline \multirow{2}{*}{ Yes } & 20 & 20 & 16 & 10 & 4 & 4 \\
\cline { 2 - 7 } & $50.0 \%$ & $50.0 \%$ & $40.0 \%$ & $25.0 \%$ & $10.0 \%$ & $10.0 \%$ \\
\hline \multirow{2}{*}{ Total } & 40 & 40 & 40 & 40 & 40 & 40 \\
\cline { 2 - 7 } & $100.0 \%$ & $100.0 \%$ & $100.0 \%$ & $100.0 \%$ & $100.0 \%$ & $100.0 \%$ \\
\hline \multicolumn{7}{|l|}{ Chi-square value $=32.276$, p-value $<0.001 *$} \\
\hline
\end{tabular}

Table 7: Comparison of Thermal Discrimination deficit at various time intervals

\begin{tabular}{|c|c|c|c|c|c|c|}
\hline Thermal Discrimination deficit & Pre-operative & 1 Week & 3 weeks & 6 weeks & 3 months & 6 months \\
\hline \multirow{2}{*}{ No } & 20 & 20 & 25 & 30 & 35 & 36 \\
\cline { 2 - 7 } & $50.0 \%$ & $50.0 \%$ & $62.5 \%$ & $75.0 \%$ & $87.5 \%$ & $90.0 \%$ \\
\hline \multirow{3}{*}{ Yes } & 20 & 20 & 15 & 10 & 5 & 4 \\
\cline { 2 - 7 } & $50.0 \%$ & $50.0 \%$ & $37.5 \%$ & $25.0 \%$ & $12.5 \%$ & $10.0 \%$ \\
\hline \multirow{2}{*}{ Total } & 40 & 40 & 40 & 40 & 40 & 40 \\
\cline { 2 - 6 } & $100.0 \%$ & $100.0 \%$ & $100.0 \%$ & $100.0 \%$ & $100.0 \%$ & $100.0 \%$ \\
\hline
\end{tabular}


Table 8: Comparison of pin prick deficit at various time intervals

\begin{tabular}{|c|c|c|c|c|c|c|}
\hline Pin prick deficit & Pre-operative & 1 Week & 3 weeks & 6 weeks & 3 months & 6 months \\
\hline \multirow{2}{*}{ No } & 20 & 20 & 23 & 28 & 33 & 36 \\
\cline { 2 - 7 } & $50.0 \%$ & $50.0 \%$ & $57.5 \%$ & $70.0 \%$ & $82.5 \%$ & $90.0 \%$ \\
\hline \multirow{2}{*}{ Yes } & 20 & 20 & 17 & 12 & 7 & 4 \\
\cline { 2 - 7 } & $50.0 \%$ & $50.0 \%$ & $42.5 \%$ & $30.0 \%$ & $17.5 \%$ & $10.0 \%$ \\
\hline \multirow{2}{*}{ Total } & 40 & 40 & 40 & 40 & 40 & 40 \\
\cline { 2 - 7 } & $100.0 \%$ & $100.0 \%$ & $100.0 \%$ & $100.0 \%$ & $100.0 \%$ & $100.0 \%$ \\
\hline \multicolumn{7}{|l}{ Chi-square value $=19.987$, p-value $=0.001 *$} \\
\hline
\end{tabular}

Table 9: Distribution of patients with regard to the displacement of fracture

\begin{tabular}{|c|c|c|}
\hline Displacement of Fracture & Frequency & Percent \\
\hline Displacement $<5 \mathrm{~mm}$ & 23 & $57.5 \%$ \\
\hline Displacement $>5 \mathrm{~mm}$ & 7 & $17.5 \%$ \\
\hline Without Displacement & 10 & $25.0 \%$ \\
\hline Total & 40 & $100.0 \%$ \\
\hline
\end{tabular}

Table 10: Distribution of patients with regard to the choice of treatment

\begin{tabular}{|c|c|c|}
\hline Treatment & Frequency & Percent \\
\hline CR with MMF & 33 & $82.5 \%$ \\
\hline ORIF & 7 & $17.5 \%$ \\
\hline Total & 40 & $100.0 \%$ \\
\hline
\end{tabular}

\section{Conclusion}

The results of this study suggest that for most patients the IAN neurosensory status is unchanged or improved after mandibular fracture treatment compared with the patient's postinjury/pre-treatment neurosensory status. In the case, however, where IAN neurosensory status deteriorates after treatment, fracture displacement, the postinjury/pre-treatment neurosensory status, and treatment are risk factors. Interestingly, only one of these factors (i.e, treatment) is under the control of the clinician. Although ORIF was associated with an increased risk for worsening of the IAN neurosensory score after treatment, this finding must be tempered by the benefits associated with ORIF (e.g, immediate function). The neurosensory changes noted in this study, however, could be temporary and the long-term outcome is unknown.

\section{References}

1. Meisami T, Sojat A, Sandor G, Lawrence H, Clokie C. Impacted Third molars and risk of angle fracture. Int. J Oral Maxillofac. Surg 2002; 31:140-144.

2. Barber HD, Baharam R, Woodbury SC, Silverstein KE, Fonseca RJ. (ed.). Mandibular fractures. Missouri, ElsivierInc 2005;3(1):485-524.

3. Rowe L, Williams J. Fractures of Mandible. USA, ElsivierInc 1985;1:10-13.

4. Scott RA, Teo N, Perry M. Displacement of mandibular fractures: is there a correlation with sensory loss and recovery? Int. J. Oral Maxillofac. Surg 2014;43:555-558.

5. Mayrink G, Moreira RW, Araujo MM. Prospective study of postoperative sensory dis-turbances after surgical treatment of mandibular fractures. Oral MaxillofacSurg 2013;17(1):27-31.

6. Marchena JM, Padwa BL, Kaban LB. Sensory abnormalities associated with mandible fractures: Incidence and natural history. J Oral Maxillofac Surg 1998;56:822-25.

7. Campbell RL, Shamaskin RG, Harkins SW. Assessment of recovery from injury to inferior alveolar \& mental nerves. Oral Surgery Oral Med Oral Pathol 1987;64(5):519-26.
8. Zuniga JR, Meyer RA, Gregg JM, Miloro M, Davis LF. Zuniga, Meyer: The accuracy of clinical neurosensory testing of nerve injury diagnosis. J Oral Maxillofacial Surg 1998;56(1):2-8.

9. Nishioka G, Zysset M, Sickels J. Neurosensory disturbances with rigid fixation of the bilateral sagittal split osteotomy. J Oral MaxillofacSurg 1987;45:20-26.

10. Dodson TB, Perrott DH, Kaban LB, Gordon NC. Fixation of mandible fractures: A comparative analysis of rigid internal fixation and standard fixation techniques. J Oral Maxillofac Surg 1990;48(4):362-6.

11. Poort LJ, Neck JW, Wal KG. Sensory testing of inferior alveolar nerve injuries. A review of methods used in prospective studies. J Oral Maxillofac Surg 2009;67(2):292-300.

12. Ghali GE, Epker BN. Clinical neurosensory testing: practical applications. J Oral MaxillofacSurg 1989;47:1074-1079.

13. Zuniga JR, Essick GK. A contemporary approach to the clinical evaluation of trigeminal nerve injuries. Oral Maxillofac Surglin North Am 1992;4(2):353-56.

14. Mackinnon SE, Dellon AL. Surgery of the Peripheral Nerve. New York, Thieme Medical Publishers 1988.

15. Seddon HJ. Three types of nerve injury. Brain 1943;66:237-288.

16. Sunderland S. A classification of peripheral nerve injuries producing loss of function, Brain. 1995;74(4):491-516.

17. Svane TJ, Wolford LM, Milam SB, Bass RK. Fascicular characteristics of human inferior alveolar nerve. J Oral Maxillofac Surg 1986;44(6):431-434.

18. Robinson PP. Observations on the recovery of sensation following inferior alveolar nerve injuries. $\mathrm{Br} \mathrm{J}$ Oral MaxillofacSurg 1988;26(3):177-89.

19. Westermark A, Bystedt $\mathrm{H}$, von Konow $\mathrm{L}$. Inferior alveolar nerve function after mandibular osteotomies. $\mathrm{Br}$ J Oral MaxillofacSurg 1998;36 (6):425-8.

20. Schultze-Mosgau S, Erbe M, Rudolph D, Ott R, Neukam FW. Prospective study on post-traumatic and postoperative sensory disturbances of the inferior alveolar nerve and infraorbital nerve in mandibular and midfacial fractures. J Craniomaxillofac Surg 1999;27:8693.

21. Westermark A, Englesson L, Bongenhielm U. Neurosensory function after sagittal split osteotomy of the mandible: A comparison between subjective evaluation and objective assessment. Int $\mathrm{J}$ Adult OrthodonOrthognath Surg 1999;14(4):268-75.

22. Acebal-Binaco F, Vuylsteke PL, Mommaerts MY, De Clercg CA. Perioperative complications in corrective facial orthopedic surgery: a 5-year retrospective study. J Oral Maxillofac Surg 2000;58(7):754-60.

23. Akal UK, Sayan NB, Aydogan S, Yaman Z. Evaluation of the neurosensory deficiencies of oral and maxillofacial region following surgery, lnt J Oral Maxillofac. Surg 
2000;29(5):331-336.

24. Wong KH. Mandible fractures: A 3 year retrospective study of cases seen in oral surgical unit in Singapore. Singapore Dent J 2000;23:6-10.

25. Halpern LR, Kaban LB, Dodson TB. Perioperative neurosensory changes associated with treatment of mandibular fractures. J Oral Maxillofac Surg 2004;62(5):576-81.

26. Leslie RH, Leonard BK, Thomas BD. Peri-operative neurosensory changes associated with treatment of mandibular fractures. J Oral Maxillofac Surg 2004;62:576-81.

27. Renzi G, Carboni A, Perugini M, Giovannetti F, Becelli R. Posttraumatic Trigeminal Nerve Impairment: A prospective analysis of recovery patterns in a series of 103 consecutive facial fractures. $J$ Oral and MaxillofacSurg 2004;62:1341-1346.

28. Razukevicius D. Damage of inferior alveolar nerve in mandibular fracture cases. Stomatologia, Baltic dental and Maxillofacial Journal 2004;6:122-25.

29. Renton T, Yilmaz Z. Profiling of patients presenting with posttraumatic neuropathy of the trigeminal nerve. $J$ Orofac Pain 2011;25(4):333-44.

30. Bede SYH, Ismael WK, Al-Assaf DA, Omer SS. Inferior alveolar nerve injuries associated with mandibular fractures. J Craniofac Surg 2012;23(6):1776-8.

31. Calabria F, Sellek L, Gugole F, Trevisol L, Bertolasi L, D'Agostino A. The Use of Sensory Action Potential to Evaluate Inferior Alveolar Nerve Damage AfterOrthognathic Surgery. J Craniofac Surg 2013;24:514Y-517.

32. Rehman A, Noreen R, Ahmad T, Shah S, Din Q. Inferior alveolar nerve injury in mandibular angle fractures - A study. JKCD 2013;4:1.

33. Zuniga JR, Labanc JP. Advances in microsurgical nerve repair. J Oral Maxillofac Surg 1993;51:62-8.

34. Rehman A, Noreen R, Ahmad T, Din Q. Post traumatic inferior alveolar nerve impairment and recovery pattern in mandibular fractures. JKCD 2014;4:2. 